FY08 to 4.86 FY11) and an improved employee engagement score (68\% FY09 to $76 \%$ FY11).

Significance An organised, long term, integrated wellness programmes contributed to the improved health and wellbeing in the BNZ workforce.

\title{
IMPACT OF WELLNESS PROGRAMME TO EMPLOYEE
} HEALTH

doi:10.1136/injuryprev-2012-040580c.40

E Lilic*. BNZ OSH and Wellness Manager, Deloitte Building, 80 Queen St, Auckland, New Zealand

Background The BNZ MyWellBeing Programme was developed as a response to an increasing number of health issues in the population, particularly associated with chronic illnesses and sedentary work.

Aim To stimulate employees to proactively manage their health risks, provide tools to modify personal lifestyle behaviour and to mitigate identified health risks for the future.

Methods Organisation wide 'On-line Health Questionnaire' survey covering 11 health areas; Quality of Life, Job Satisfaction, Smoking, Weight, Average Body Mass Index (BMI), Activity, Cholesterol, Blood Pressure, Eating Habits, Stress Management and Work Related Stress. Following the identification of the health risks, a targeted programme was developed including workshops and a customised web site to deliver individual awareness and health information to employees and their families. Development of a supporting programme also included sporting events, nutrition guidance, health articles and themes, physical and intellectual challenges, etc.

Results Health data indicated reduction in smokers (12.1\% FY07 to 9.2\% FY11), poor cholesterol levels (17.1-7.1\%), poor blood pressure (13.4-9.5\%) as well as observed improvement in activity levels and healthier eating habits. Very good outcomes were evident through a reduction in the FTE sick days (Average Sick Leave per FTE-5.73 